\title{
Lipids, thrombosis and cardiovascular disease in diabetes
}

\author{
BY JOHN S. YUDKIN \\ Department of Medicine, University College London Medical School, G Block, Archway Wing, \\ Whittington Hospital, Archway Road, London N19 3UA
}

Diabetes is associated with a two- to five-fold increase in mortality from CHD (Fuller $e$ t al. 1980), an excess risk which does not appear to be explained by the well-recognized abnormalities of the other cardiovascular risk factors in diabetic patients (Rosengren et al. 1989). Lipoprotein abnormalities are common in subjects with non-insulin-dependent diabetes mellitus (NIDDM). The major changes seen in this condition are an increase in concentrations of the triacylglycerol-rich lipoproteins, in particular VLDL, a particle which itself is probably not atherogenic. Nevertheless, increased concentrations of VLDL are associated with other lipoprotein abnormalities in NIDDM, including triacylglycerol enrichment of LDL and a consequent increase in oxidizability, as well as with a reduction in concentration of HDL. Both of these are potentially atherogenic. Moreover, the increase in VLDL concentration found in NIDDM induces abnormalities of coagulation and fibrinolysis, which, by producing a procoagulant state, may further contribute to the increased incidence of CHD. The role of these changes in explaining the excess risk, along with the possible therapeutic implications, will be explored in the present article.

\section{LIPOPROTEIN ABNORMALITIES IN NON-INSULIN-DEPENDENT DIABETES MELLITUS}

Although levels of total cholesterol are similar in diabetic and non-diabetic subjects, disturbances in the subclasses of cholesterol are common in NIDDM. Concentrations of HDL-cholesterol are reduced (Laakso et al. 1993), and there is an increase in the proportion of small dense LDL particles, which may be particularly related to cardiovascular risk (Austin et al. 1995). These abnormalities may both be the consequence of impaired removal of non-esterified fatty acids from triacylglycerol-rich lipoproteins through subnormal activity of lipoprotein lipase ( $E C$ 3.1.1.34), and resulting triacylglycerol enrichment of IDL and LDL (Feingold et al. 1992). The role of reduced activity of lipoprotein lipase is also evident in the other major abnormality of lipoproteins in NIDDM, i.e. hypertriacylglycerolaemia, in particular after a fatty meal (Tan et al. 1995). All these lipid abnormalities are related to insulin resistance (Stewart et al. 1993), are commoner in obese subjects, and antedate the development of the diabetic state (Haffner et al. 1990).

\section{DYSLIPIDAEMIA AND CHD IN NON-INSULIN-DEPENDENT DIABETES MELLITUS: EPIDEMIOLOGICAL OBSERVATIONS}

The relationships between CHD and high concentrations of total and LDL-cholesterol have been well defined, with an increase of about $3 \%$ in CHD incidence and mortality with every $1 \%$ increase in LDL-cholesterol (Law et al. 1994). The relationship between cholesterol concentrations and CHD has been compared for more than 5000 diabetic and 348000 non-diabetic men screened for the Multiple Risk Factor Intervention Trial (MRFIT; Stamler et al. 1993). Although the proportional increase in CHD risk per unit increase in cholesterol concentration was smaller in the diabetic subjects, the higher background risk implied that the absolute increase per unit change in cholesterol was 


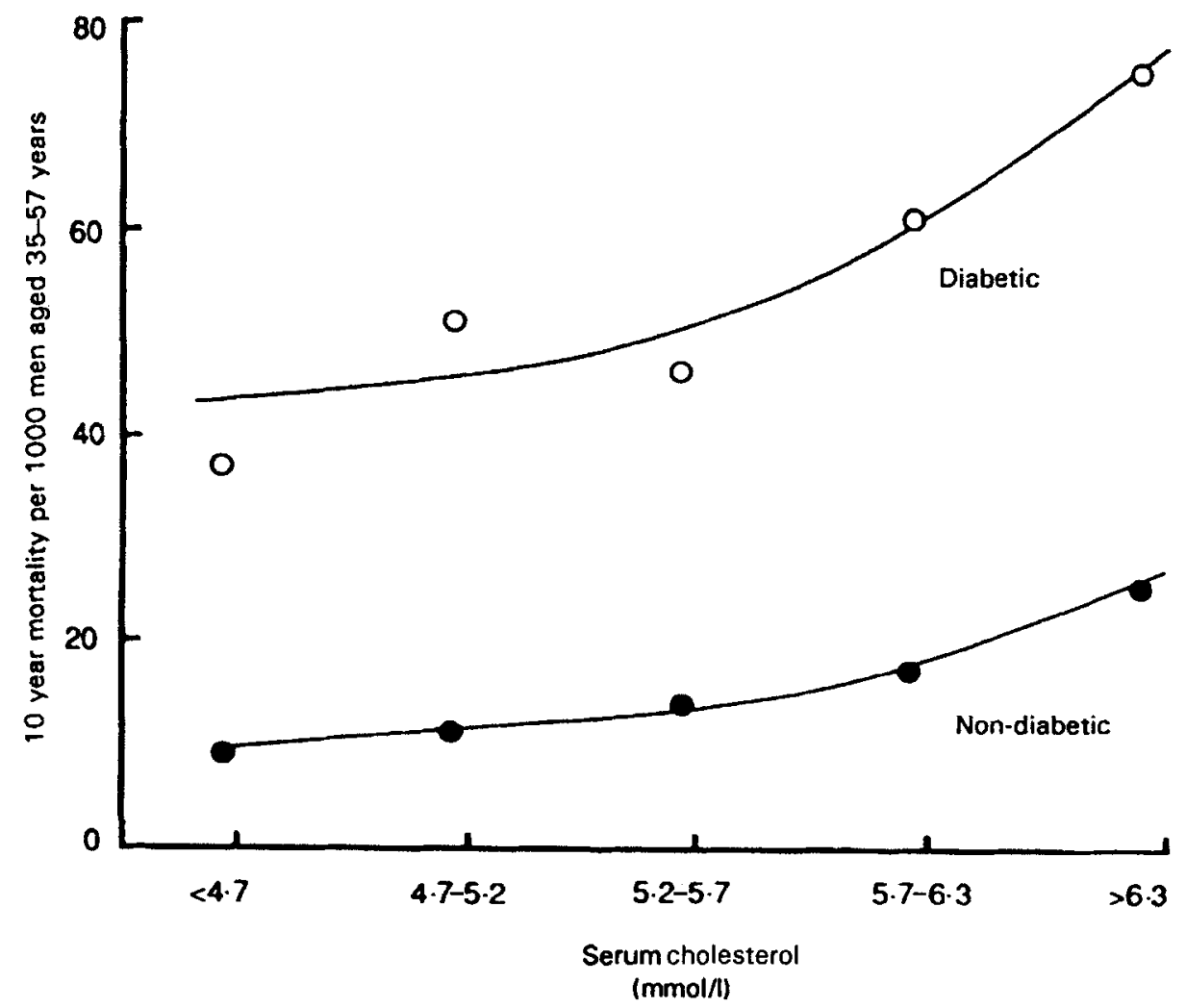

Fig. 1. Serum cholesterol and 10-year coronary heart disease mortality in 342815 non-diabetic and 5163 diabetic men aged 35-57 years. (From J. D. Neaton, personal communication.)

greater in diabetes (Fig. 1). The therapeutic implications of this observation will be considered later (p. 278).

Several studies support the importance of triacylglycerol-rich lipoproteins in predicting CHD in patients with NIDDM. Thus, a Finnish study found that in multiple-regression analysis, LDL-triacylglycerols, but not LDL- or HDL-cholesterol, predicted 5-year incidence of CHD (Uusitupa et al. 1990), while a parallel study from the same group found that high triacylglycerol concentration $(>2.3 \mathrm{mmol} / \mathrm{l})$ but not a high LDL-cholesterol (>4.1 mmol/1) predicted incident CHD over 7 years (Laakso et al. 1993). In the Paris Prospective Study of 943 subjects with abnormal glucose tolerance, a triacylglycerol level above the median $(>1.39 \mathrm{mmol} / 1)$, but not an elevated cholesterol concentration ( $>5.7 \mathrm{mmol} / \mathrm{l}$ ), was significantly predictive of 11 -year CHD mortality (Fontbonne et al. 1989).

\section{MECHANISMS OF ASSOCIATION: ATHEROGENESIS}

It is generally accepted that LDL, and not VLDL, is an atherogenic particle. Furthermore, the use of multiple-regression techniques will tend to reduce the predictive associations of variables such as triacylglycerols, which have a high biological variability (Austin, 1989). Thus, the finding that concentrations of triacylglycerol-rich lipoproteins predict CHD in 
three separate longitudinal studies of NIDDM and glucose intolerance are at first difficult to understand.

The mechanism of vessel-wall damage by LDL-cholesterol is incompletely understood. Certain subfractions, and in particular small dense LDL, appear to be most harmful (Austin et al. 1990), perhaps because these particles are substantially more vulnerable to lipid oxidation (Steinberg et al. 1989). Whether this, in turn, is because of increased content of oxidizable fatty acids, or due to lower content of antioxidants, is unclear. The elevated triacylglycerol concentrations found in NIDDM patients are associated with increased proportions of small dense LDL (Austin et al. 1995; Lahdenperä et al. 1995), with increased lipid oxidation and reduced concentrations of antioxidants in these particles (Chait et al. 1993), these perhaps representing the mechanisms of association of CHD with hypertriacylglycerolaemia in these patients.

\section{MECHANISMS OF ASSOCIATION: THROMBOGENESIS AND IMPAIRED FIBRINOLYSIS}

Hypertriacylglycerolaemia is associated with a number of abnormalities of coagulation and fibrinolysis. Thus, Factor VII coagulant activity is increased in proportion to triacylglycerol concentration, perhaps consequent on activation of the serine protease, which cleaves the Factor VII precursor to the active molecular species, by binding to the surface of the VLDL particle (Miller et al. 1986). Plasminogen activator inhibitor-1 (PAI-1) is a fast-acting inhibitor of fibrinolysis, which alters the thrombotic balance in favour of occlusion. Levels of PAI- 1 are elevated in young men surviving a myocardial infarction and also predict recurrent events (Hamsten et al. 1987). We have found that increased PAI-1 activity in patients admitted to hospital with acute myocardial infarction predicts a poor response to thrombolytic therapy, and that elevated levels on the third day after the initial event predict in-hospital re-infarction (Gray et al. 1993b). Levels of PAI-1 are increased in NIDDM patients (Gray et al. 1993c), and further increased in diabetic patients with CHD (Gray et al. 1993a). We have found that diabetic patients show enzymic evidence of poorer response to thrombolysis than do non-diabetic subjects, which is largely related to their higher admission levels of PAI-1 (Gray et al. 1993b).

PAI-1 is expressed in, and synthesized by, both liver and endothelium. In hepatocytes, PAI-1 synthesis is increased by inducing insulin resistance (Anfossa et al. 1993), a relationship which has also been noted in clinical studies (Juhan-Vague et al. 1993; Potter van Loon et al. 1993). However, the interpretation of such clinical studies is made complex by the powerful interrelationships between various features of the insulin-resistance syndrome, any of which may explain the increased levels of PAI-1 in insulin resistance and in NIDDM. Thus, PAI-1 activity relates to elevated concentrations of triacylglycerol (Vague et al. 1986; Asplund-Carlson et al. 1993), to central and global obesity (Folsom et al. 1993) and to hyperproinsulinaemia (Nagi et al. 1990). Expression studies and investigation of tissue culture have been able to resolve some of these issues, demonstrating, for example, that both VLDL particles from hypertriacylglycerolaemic subjects (Stiko-Rahm et al. 1990) and oxidized LDL particles (Latron et al. 1991) are able to induce secretion of PAI-1 from cultured human umbilical-vein endothelial cells. There appear to be important gene-environment interactions in this mechanism, in that NIDDM patients homozygous for a common allele (4G) located 675 base pairs upstream from the start of transcription of the PAI-1 gene showed higher levels of PAI-1, and greater impact of hypertriacylglycerolaemia, than those homozygous for the 5G allele (Panahloo et al. 1995). It appears, then, that hypertriacylglycerolaemia, and the parallel increase in the proportion of oxidized small dense LDL, may help directly to explain the elevated levels of 
PAI-activity and the impaired fibrinolysis seen in NIDDM (Panahloo \& Yudkin, 1996), this perhaps being especially relevant in those with the 4G4G PAI-1 genotype.

\section{MECHANISMS OF ASSOCIATION: ENDOTHELIAL DYSFUNCTION AS A COMMON ANTECEDENT?}

Associations are not proof of causation, and it may be hypothesized that the relationship between hypertriacylglycerolaemia, insulin resistance, elevated levels of PAI-1 and cardiovascular risk could represent consequences of a common antecedent. Skeletalmuscle blood flow makes an important contribution to insulin action, with the effects of insulin including an increase in muscle blood flow, thereby increasing supply of both substrate and hormone to the insulin-sensitive tissues (Laakso et al. 1992). Insulin needs to be translocated to the abluminal side of the capillary to access the cell receptor, and part of this transport is via an energy-dependent receptor-mediated transpinocytosis (King \& Johnson, 1985). Insulin transport across endothelium may be rate-limiting for its action during changes in insulin concentration (Ader \& Bergman, 1994). Damage to capillary or resistance vessel endothelium might thereby impair insulin action. Parallel changes in adipose tissue might adversely affect the proteoglycan binding of the exoenzyme lipoprotein lipase, which would impair the clearance of triacylglycerol-rich lipoproteins (Eckel, 1989). Furthermore, the activation of endothelial expression of PAI-1 by cytokines or by other participants in endothelial damage or acute-phase reaction (Sawdey \& Loskutoff, 1991) could partly underlie the relationships between insulin resistance, hypertriacylglycerolaemia and impaired fibrinolysis. In thirty-three subjects with NIDDM, we have found significant relationships between concentrations of von Willebrand factor, a marker of endothelial dysfunction, and the degree of insulin resistance as measured by the modified Harano method (Fig. 2), as well as between levels of von Willebrand factor and those of triacylglycerol $\left(r_{s}-0.36, P=0.04\right)$, providing support for the hypothesis of an endothelial aetiology of both insulin resistance and the metabolic syndrome.

It could be postulated that the process of endothelial damage could both initiate and compound the atherothrombotic process. Thus, a loss of endothelially-bound lipoprotein lipase might be responsible for an accumulation of triacylglycerol-rich lipoprotein, with consequent enhanced oxidation of small dense LDL and reduced levels of HDL increasing the damage to endothelium and deposition of fatty plaques. There is accumulating evidence that markers of inflammation indicate an increased risk of CHD events (Mendall et al. 1996), maybe in part by damage to endothelium or matrix by activated macrophages (Casscells et al. 1996), but perhaps also as a consequence of the compounding effects of the acute-phase protein, fibrinogen, on the atherothrombotic process (Casscells et al. 1996), and those of the inflammatory cytokines on expression of another pro-coagulant molecule, PAI-1. In Table 1 are shown the complex interrelationships between markers of the acutephase response (C-reactive protein and fibrinogen) and of endothelial damage (von Willebrand factor, fibronectin, thrombomodulin) with insulin resistance (fasting insulin concentrations) and the cardiovascular risk markers under consideration (triacylglycerol, PAI-1) in 125 Caucasian non-diabetic subjects recruited from general practice. From these data it appears that elevated levels of acute-phase proteins correlate with markers of endothelial damage, and that both are correlated with hyperinsulinaemia, an indicator of insulin resistance. Furthermore, elevated levels of triacylglycerol and of PAI-1 appear to relate both to hyperinsulinaemia and to endothelial dysfunction and/or inflammation. 


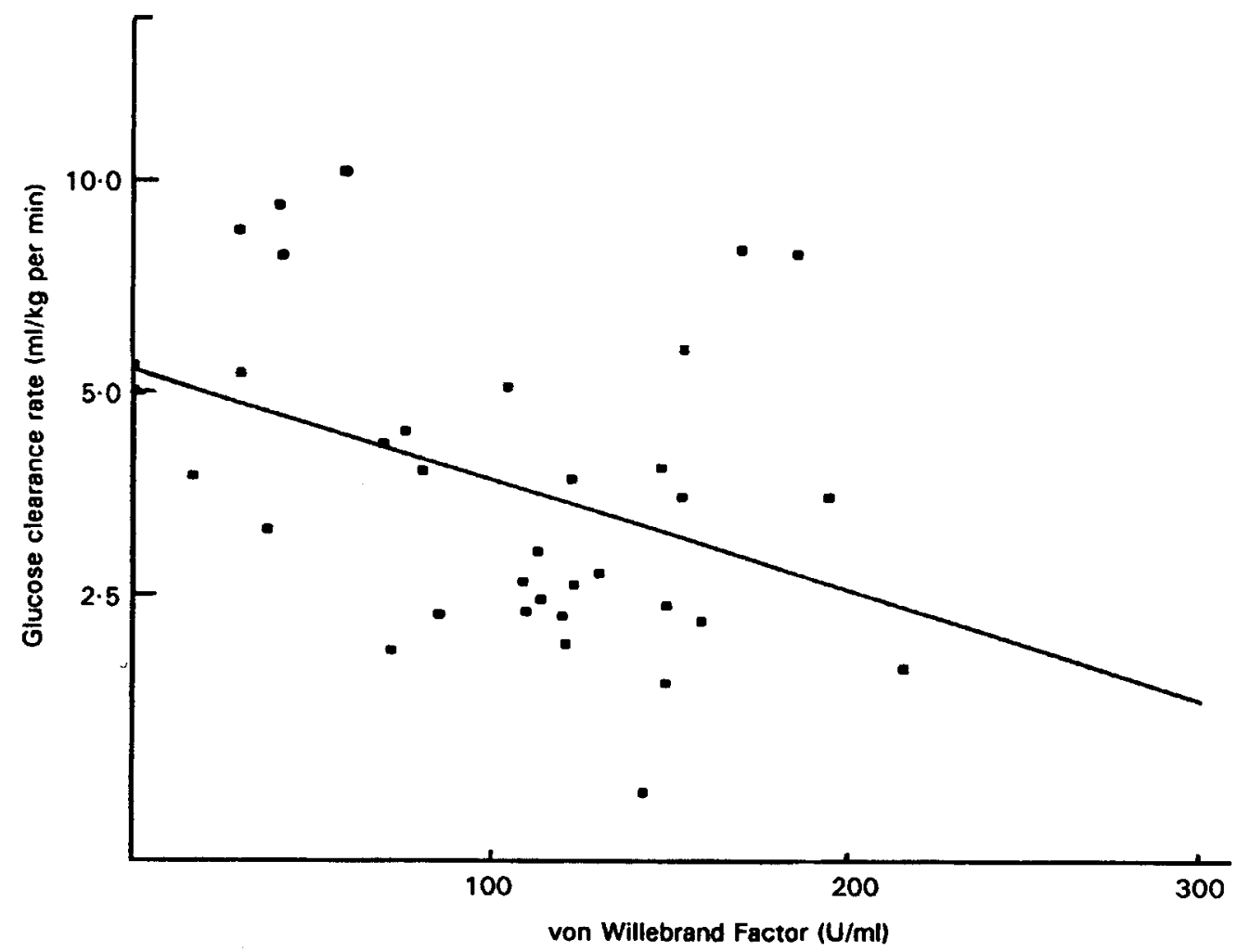

Fig. 2. The relationship between von Willebrand factor (marker of endothelial dysfunction) levels and metabolic clearance rate of glucose in thirty-three non-insulin-dependent diabetic subjects. $r-0.35, P=0.048$.

Table 1. Relationship between markers of cardiovascular risk, endothelial damage, and inflammation in 123 non-diabetic subjects

\begin{tabular}{|c|c|c|c|c|c|c|}
\hline & Insulin & Triacylglycerol & Fibronectin & vWF & CRP & $\begin{array}{c}\text { Fibrino- } \\
\text { gen }\end{array}$ \\
\hline Fasting insulin $\dagger$ & - & $0.41 * * *$ & $0.23^{*}$ & 0.12 & $0.22 *$ & $0.20^{*}$ \\
\hline Triacylglycerol $\dagger$ & $0.41 * * *$ & - & $0.32 * * *$ & 0.14 & $0.27 * *$ & $0 \cdot 20^{*}$ \\
\hline PAI- $1 \dagger$ & $0.42 * * *$ & $0.34 * * *$ & 0.03 & 0.03 & $0.21 *$ & $0 \cdot 15^{*}$ \\
\hline Fibronectin $\uparrow$ & & & - & $0.30^{* *}$ & $0 \cdot 29 * *$ & 0.12 \\
\hline vWF & & & $0.30 * *$ & - & $0.31 * * *$ & 0.16 \\
\hline CRP† & & & & & - & $0.22 *$ \\
\hline Fibrinogen & & & & & $0 \cdot 22 *$ & - \\
\hline
\end{tabular}

PAI-1, plasminogen activator inhibitor-1; vWF, von Willebrand factor (marker of endothelial dysfunction); CRP, Creactive protein.

$* P<0.05, * * P<0.01, * * * P<0.001$.

†Variable logarithmically transformed.

\section{DYSLIPIDAEMIA IN NON-INSULIN-DEPENDENT DIABETES MELLITUS: IMPLICATIONS FOR THERAPY}

While LDL-cholesterol concentrations are similar in diabetic and non-diabetic subjects, as pointed out previously, the findings of two new studies have provided clear indications for cholesterol lowering in high-risk subjects (Scandinavian Simvastatin Survival Study 
Group, 1994; Shepherd et al. 1995). Thus, the 4S Study (Scandinavian Simvastatin Survival Study Group, 1994) used simvastatin for secondary prevention in 4444 men, demonstrating a $32 \%$ reduction in cardiovascular mortality over 5 years. The West of Scotland Pravastatin Study (Shepherd et al. 1995) showed similar proportional benefits in a primary prevention setting. A subgroup analysis of the 4S Study, assessing the benefits of these drugs in about 200 diabetic patients with $\mathrm{CHD}$ and a total cholesterol concentration of $>5.5 \mathrm{mmol} / 1$ showed similar benefits to those in the non-diabetic patients in the study (Pyörälä et al. 1995). The advent of these new drugs has now made effective cholesterol lowering possible and, as a consequence, the 2 year loss of life expectancy that hypercholesterolaemia can be calculated to produce in a 45-year-old non-diabetic man, and the 16 month loss for a 45-year-old diabetic (Yudkin, 1993) might in theory be reversed by more than half by these hydroxymethylglutaryl-CoA inhibitors.

The interpretation of the relationships between hypertriacylglycerolaemia and CHD in diabetic patients clearly has a major impact on therapy. If lowering of elevated levels of triacylglycerol were capable of producing elevation of HDL-cholesterol, reduced proportions or oxidation of small dense LDL, and reductions in levels of PAI-1 and Factor VII, these more proximal markers of CHD risk could provide more meaningful surrogate risk markers than levels of triacylglycerol itself. If, however, the elevated concentrations of triacylglycerol provided an indication of pre-existing endothelial damage, then their reduction may be without benefit. It is only through the establishing of intervention trials with hard endpoints that such conclusions could be reached.

\section{CONCLUSION}

The complexities of the atherothrombotic process continue to be unravelled in directions not predicted by the cholesterol-heart hypothesis. Fibrinolysis, oxidation, inflammation and endothelial dysfunction are all major players in the game, and the data are not yet available to decide whether some of the lipid and fibrinolytic markers, such as triacylglycerol and PAI-1, are true risk factors, defined on the basis of reversibility and experimentation (Bradford Hill, 1965).

\section{REFERENCES}

Ader, M. \& Bergman, R. N. (1994). Importance of transcapillary insulin transport to dynamics of insulin action after intravenous glucose. American Journal of Physiology 266, E17-E25.

Anfossa, F., Chomiki, N., Alessi, M. C., Vague, P. \& Juhan-Vague, I. (1993). Plasminogen activator inhibitor-1 synthesis in the human hepatoma cell line Hep G2: metformin inhibits the stimulating effect of insulin. Journal of Clinical Investigation 91, 2185-2193.

Asplund-Carlson, A., Hamsten, A., Wiman, B. \& Carlson, L. A. (1993). Relationship between plasma plasminogen activator inhibitor-1 activity and VLDL triglyceride concentration, insulin levels and insulin sensitivity: studies in randomly selected normo- and hypertriglyceridaemic men. Diabetologia 36, 817-825.

Austin, M. A. (1989). Plasma triglyceride as a risk factor for coronary heart disease. The epidemiologic evidence and beyond. American Journal of Epidemiology 129, 249-259.

Austin, M. A., King, M.-C., Vranizan, K. M. \& Krauss, R. M. (1990). Atherogenic lipoprotein phenotype: a proposed genetic marker for coronary heart disease risk. Circulation 82, 495-506.

Austin, M. A., Mykkänen, L., Kuusisto, J., Edwards, K. L., Nelson, C., Haffner, S. M., Pyörälä, K. \& Laakso, M. (1995). Prospective study of small LDLs as a risk factor for non-insulin dependent diabetes mellitus in elderly men and women. Circulation 92, 1770-1778.

Bradford Hill, A. (1965). The environment and disease: Association or causation? Proceedings of the Royal Society of Medicine 58, 295-300.

Casscells, W., Hathor, B., David, M., Krabach, T., Vaughn, W. K., McAllister, H. A., Bearman, G. \& Willerson, J. T. (1996). Thermal detection of cellular infiltrates in living atherosclerotic plaques: possible implications for plaque rupture and thrombosis. Lancet 347, 1447-1449. 
Chait, A., Brazg, R. L., Tribble, D. L. \& Krauss, R. L. (1993). Susceptibility of small, dense, low-density lipoproteins to oxidative modification in subjects with the atherogenic lipoprotein phenotype, pattern $\mathrm{B}$. American Journal of Medicine 94, 351-356.

Eckel, R. H. (1989). Lipoprotein lipase: a multifunctional enzyme relevant to common metabolic diseases. New England Journal of Medicine 320, 1060-1068.

Feingold, K. R., Grunfeld, C., Pang, M., Doerrler, W. \& Krauss, R. M. (1992). LDL subclass phenotypes and triglyceride metabolism in non-insulin-dependent diabetes. Arteriosclerosis and Thrombosis 12, $1496-1502$.

Folsom, A. R., Qamhieh, H. T., Wing, R. R., Jeffery, R. W., Stinson, V. L., Kuller, L. H. \& Wu, K. K. (1993). Impact of weight loss on plasminogen activator inhibitor (PAI-1), factor VII, and other hemostatic factors in moderately overweight adults. Arteriosclerosis and Thrombosis 13, 162-169.

Fontbonne, A., Eschwège, E., Cambien, F., Richard, J.-L., Ducimetière, P., Thibult, N., Warnet, J.-M., Claude, J.-R. \& Rosselin, G.-E. (1989). Hypertriglyceridaemia as a risk factor of coronary heart disease mortality in subjects with impaired glucose tolerance or diabetes. Diabetologia 32, 300-304.

Fuller, J. H., Shipley, M. J., Rose, G., Jarrett, R. J. \& Keen, H. (1980). Coronary-heart-disease risk and impaired glucose tolerance. The Whitehall Study. Lancet i, 1373-1376.

Gray, R. P., Patterson, D. L. H. \& Yudkin, J. S. (1993a). Plasminogen activator inhibitor activity in diabetic and nondiabetic survivors of myocardial infarction. Arteriosclerosis and Thrombosis 13, 415-420.

Gray, R. P., Yudkin, J. S. \& Patterson, D. L. (1993b). Enzymatic evidence of impaired reperfusion in diabetic patients after thrombolytic therapy for acute myocardial infarction: A role for plasminogen activator inhibitor? British Heart Journal 70, 530-536.

Gray, R. P., Yudkin, J. S. \& Patterson, D. L. H. (1993c). Plasminogen activator inhibitor: a risk factor for myocardial infarction in diabetic subjects. British Heart Journal 69, 228-232.

Haffner, S. M., Stern, M. P., Hazuda, H. P., Mitchell, B. D. \& Patterson, J. K. (1990). Cardiovascular risk factors in confirmed prediabetic individuals. Does the clock for coronary heart disease start ticking before the onset of clinical diabetes? Journal of the American Medical Association 263, 2893-2898.

Hamsten, A., de Faire, U., Walldius, G., Dahlen, G., Szamosi, A., Landou, C., Blomback, M. \& Wiman, B. (1987). Plasminogen activator inhibitor in plasma: risk factor for recurrent myocardial infarction. Lancet ii, 3-9.

Juhan-Vague, I., Thompson, S. G. \& Jespersen, J. (1993). Involvement of the hemostatic system in the insulin resistance syndrome: a study of 1500 patients with angina pectoris. Arteriosclerosis and Thrombosis 13, 1865-1873.

King, G. L. \& Johnson, S. M. (1985). Receptor-mediated transport of insulin across endothelial cells. Science 227, 1583-1586.

Laakso, M., Edleman, S. V.. Brechtel, G. \& Baron, A. D. (1992). Impaired insulin-mediated skeletal muscle blood flow in patients with NIDDM. Diabetes 41, 1076-1083.

Laakso, M., Lehto, S., Penttilä, I. \& Pyörälä, K. (1993). Lipids and lipoproteins predicting coronary heart disease mortality and morbidity in patients with non-insulin-dependent diabetes. Circulation 88, 1421-1430.

Lahdenperä, S., Sane, T., Vuorinen-Markkola, H., Knudsen, P. \& Taskinen, M. R. (1995). LDL particle size in mildly hypertriglyceridemic subjects: no relation to insulin resistance or diabetes. Atherosclerosis 113,227 236.

Latron, Y., Chautan, M., Anfosso, F., Alessi, M. C., Nalbone, G., Lafont, H. \& Juhan-Vague, I. (1991). Stimulating effect of oxidised low density lipoprotein on plasminogen activator inhibitor-1 synthesis by endothelial cells. Arteriosclerosis and Thrombosis 11, 1821-1829.

Law, M. R., Wald, N. J. \& Thompson, S. G. (1994). By how much and how quickly does reduction in serum cholesterol concentration lower risk of ischaemic heart disease? British Medical Journal 308, 367-372.

Mendall, M. A., Patel, P., Ballam, L., Strachan, D. \& Northfield, T. C. (1996). C reactive protein and its relation to cardiovascular risk factors: a population based cross sectional study. British Medical Journal 312, 10611065.

Miller, G. J., Martin, J. C., Webster. J., Wilkes, H., Miller, N. E., Wilkinson, W. H. \& Meade, T.W. (1986). Association between dietary fat intake and plasma factor VII coagulant activity - a predictor of cardiovascular mortality. Atherosclerosis 60, 269-277.

Nagi, D. K., Hendra, T. J., Ryle, A. J., Cooper, T. M., Temple, R. C., Clark, P. M. S., Schneider, A. E., Hales, C. N. \& Yudkin, J. S. (1990). The relationship of concentrations of insulin, intact proinsulin and 32-33 split proinsulin with cardiovascular risk factors in type 2 (non-insulin dependent) diabetic subjects. Diabetologia 33, 532-537.

Panahloo, A., Mohamed-Ali, V., Lane, A., Green, F., Humphries, S. E. \& Yudkin, J. S. (1995). Determinants of plasminogen activator inhibitor-1 activity in treated NIDDM and its relation to a polymorphism in the plasminogen activator inhibitor-1 gene. Diabetes $44,37-42$.

Panahloo, A. \& Yudkin, J. S. (1996). Diminished fibrinolysis in diabetes mellitus and its implication for diabetic vascular disease. Coronary Artery Disease 7, 723-731.

Potter van Loon, B. J., Kluft, C., Radder, J. K., Blankenstein, M. A. \& Meinders, A. E. (1993). The cardiovascular risk factor plasminogen activator inhibitor type 1 is related to insulin resistance. Metabolism 42, 945-949. 
Pyörälä, K., Pedersen, T. R. \& Kjekshus, J. (1995). The effect of cholesterol lowering with simvastatin on coronary events in diabetic patients with coronary heart disease. Diabetes 44, Suppl. 1, 35A Abstr.

Rosengren, A., Welin, L., Tsipogianni, A. \& Wilhelmsen, L. (1989). Impact of cardiovascular risk factors on coronary heart disease and mortality among middle aged diabetic men: a general population study. British Medical Journal 299, 1127-1131.

Sawdey, M. S. \& Loskutoff, D. J. (1991). Regulation of murine type 1 plasminogen activator inhibitor gene expression in vivo. Journal of Clinical Investigation 88, 1346-1353.

Scandinavian Simvastatin Survival Study Group (1994). Randomised trial of cholesterol lowering in 4444 patients with coronary heart disease: the Scandinavian Simvastatin Survival Study (4S). Lancet 344, 13831389.

Shepherd, J., Cobbe, S. M., Ford, I., Isles, C. G., Lorimer, A. R., Macfarlane, P. W., McKillop, J. H. \& Packard, C. J. (1995). Prevention of coronary heart disease with pravastatin in men with hypercholesterolemia. New England Journal of Medicine 333, 1301-1307.

Stamler, J., Vaccaro, O., Neaton, J. D. \& Wentworth, D. for the Multiple Risk Factor Intervention Trial Research Group (1993). Diabetes, other risk factors, and 12-yr cardiovascular mortality for men screened in the Multiple Risk Factor Intervention Trial. Diabetes Care 16, 434-444.

Steinberg, D., Parthasarathy, S., Carew, T. E., Khoo, J. C. \& Witztum, J. L. (1989). Modifications of low density lipoprotein that increase its atherogenicity. New England Joumal of Medicine 320, 915-924.

Stewart, M. W., Laker, M. F., Dyer, R. G., Game, F., Mitcheson, J., Winocour, P. H. \& Alberti, K. G. M. M. (1993). Lipoprotein compositional abnormalities and insulin resistance in type II diabetic patients with mild hyperlipidemia. Arteriosclerosis and Thrombosis 13, 1046-1052.

Stiko-Rahm, A., Wiman, B., Hamsten, A. \& Nilsson, J. (1990). Secretion of plasminogen activator inhibitor-1 from cultured human umbilical vein cells is induced by very low density lipoprotein. Arteriosclerosis 10, 1067-1073.

Tan, K. C. B., Cooper, M. B., Ling, K. L. E., Griffin, B. A., Freeman, D. J., Packard, C. J., Shepherd, J., Hales, C. N. \& Betteridge, D. J. (1995). Fasting and postprandial determinants for the occurrence of small dense LDL species in non-insulin-dependent diabetic patients with and without hypertriglyceridaemia: the involvement of insulin, insulin precursor species and insulin resistance. Atherosclerosis 113, 273-287.

Uusitupa, M. I. J., Niskanen, L. K., Siitonen, O., Voutilainen, E. \& Pyörälä, K. (1990). 5-year incidence of atherosclerotic vascular disease in relation to general risk factors, insulin level, and abnormalities in lipoprotein composition in non-insulin-dependent diabetic and nondiabetic subjects. Circulation 82, 27-36.

Vague, Ph., Juhan-Vague, I., Aillaud, M. F., Badier, C., Viard, R., Alessi, M. C. \& Collen, D. (1986). Correlations between blood fibrinolytic activity, plasminogen activator inhibitor levels, plasma insulin and relative body weight in normal and obese subjects. Metabolism 35, 250-253.

Yudkin, J. S. (1993). How can we best prolong life? The benefits of coronary risk factor reduction in nondiabetic and diabetic subjects. British Medical Journal 306, 1313-1318. 